\title{
Transcriptomic changes in Cucurbita pepo fruit after cold storage: differential response between two cultivars contrasting in chilling sensitivity
}

\author{
F. Carvajal ${ }^{1 \dagger}$, R. Rosales ${ }^{1 \dagger}$, F. Palma', S. Manzano², J. Cañizares ${ }^{3}$, M. Jamilena ${ }^{2}$ and D. Garrido ${ }^{1 *}$
}

\begin{abstract}
Background: Zucchini fruit is susceptible to chilling injury $(\mathrm{Cl})$, but the response to low storage temperature is cultivar dependent. Previous reports about the response of zucchini fruit to chilling storage have been focused on the physiology and biochemistry of this process, with little information about the molecular mechanisms underlying it. In this work, we present a comprehensive analysis of transcriptomic changes that take place after cold storage in zucchini fruit of two commercial cultivars with contrasting response to chilling stress.

Results: RNA-Seq analysis was conducted in exocarp of fruit at harvest and after 14 days of storage at 4 and $20^{\circ} \mathrm{C}$. Differential expressed genes (DEGs) were obtained comparing fruit stored at $4^{\circ} \mathrm{C}$ with their control at $20^{\circ} \mathrm{C}$, and then specific and common up and down-regulated DEGs of each cultivar were identified. Functional analysis of these DEGs identified similarities between the response of zucchini fruit to low temperature and other stresses, with an important number of GO terms related to biotic and abiotic stresses overrepresented in both cultivars. This study also revealed several molecular mechanisms that could be related to chilling tolerance, since they were up-regulated in $\mathrm{cv}$. Natura (Cl tolerant) or down-regulated in $\mathrm{Cv}$. Sinatra (Cl sensitive). These mechanisms were mainly those related to carbohydrate and energy metabolism, transcription, signal transduction, and protein transport and degradation. Among DEGs belonging to these pathways, we selected candidate genes that could regulate or promote chilling tolerance in zucchini fruit including the transcription factors MYB76-like, ZAT10-like, DELLA protein GAIP, and AP2/ERF domain-containing protein.
\end{abstract}

Conclusions: This study provides a broader understanding of the important mechanisms and processes related to coping with low temperature stress in zucchini fruit and allowed the identification of some candidate genes that may be involved in the acquisition of chilling tolerance in this crop. These genes will be the basis of future studies aimed to identify markers involved in cold tolerance and aid in zucchini breeding programs.

Keywords: Zucchini fruit, Postharvest physiology, Cold tolerance, Transcriptomic profiling, Stress response

\section{Background}

Refrigerated storage is considered to be the most effective method for preserving the quality of fruit and vegetables, allowing long-distance transport and thus a more regulated supply of commodities in the market. However, fruit from tropical and subtropical origins are prone to chilling

\footnotetext{
* Correspondence: dgarrido@ugr.es

${ }^{\dagger}$ Equal contributors

'Department of Plant Physiology, Facultad de Ciencias, University of Granada, Fuentenueva s/n, 18071 Granada, Spain

Full list of author information is available at the end of the article
}

injury (CI) during storage at low, non-freezing temperatures, as is the case for zucchini squash (Cucurbita pepo L.). Fruit from this species are marketed at an immature stage and are susceptible to developing CI symptoms when stored at low temperature, including peel pitting, weight loss, and softening [1,2]. Previous research has focused on unraveling some of the mechanisms associated with the response of zucchini fruit to cold stress, revealing that the exposure of zucchini fruit to chilling results in a series of ultra-structural, physiological, and biochemical 
modifications common to other stresses such as an accumulation of hydrogen peroxide $\left(\mathrm{H}_{2} \mathrm{O}_{2}\right)$ and malondialdehyde (MDA), as well as changes in the levels of endogenous abscisic acid [3, 4], ethylene $[5,6]$, polyamines [7] and in soluble sugars [8]. Moreover, previous works have demonstrated the existence of genetic variability for CI tolerance among commercial and local cultivars of zucchini squash $[6,9]$. The fruit of the most CI-tolerant cultivars produces less chilling-induced ethylene and accumulates lower content of $\mathrm{H}_{2} \mathrm{O}_{2}$ and MDA, two metabolites associated with oxidative stress. Among commercial hybrids, fruit from Natura showed very low CI after 14 days of cold exposure, while fruit from cv. Sinatra presented high CI index and an important loss of fruit quality [9]. Subsequent physiological research revealed many differences between these two cultivars in some metabolic pathways involved in chilling stress and tolerance, confirming that Natura and Sinatra should be considered tolerant and sensitive cultivars to cold stress, respectively. In this sense, Natura fruit has higher soluble sugar content, higher levels of proline, lower content in chilling stress metabolites such as $\mathrm{H}_{2} \mathrm{O}_{2}$ or MDA, and higher gene expression and activity of antioxidant defense enzymes, than Sinatra fruit $[7,10,11]$. In relation to the hormones involved in cold tolerance, it has been reported that the fruit of the most CI-tolerant cultivars shows a reduced induction of ethylene biosynthesis and signaling pathways under cold storage, and that the treatment with 1MCP prevents chilling damage $[6,11]$. Recently we have also detected an increase in the synthesis of abscisic acid (ABA) during the first days of cold storage in the more cold-tolerant cultivar [3]. Hence, there is an increasing amount of information concerning the physiology and biochemistry of chilling in zucchini fruit, however, the molecular mechanisms underlying the response of zucchini fruit to chilling storage is limited to specific molecular pathways, including those of ethylene biosynthesis and signaling $[5,6]$, enzymatic antioxidant system [12, 13], abscisic acid synthesis and signaling, and polyamine metabolism $[3,7]$.

In the present work, fruit of the CI-tolerant and sensitive cultivars Natura and Sinatra were stored at chilling $\left(4{ }^{\circ} \mathrm{C}\right)$ and non-chilling $\left(20{ }^{\circ} \mathrm{C}\right)$ temperature for 14 days, and their transcriptomic profiles examined by RNA-Seq. The analysis of the transcriptomic changes in response to cold stress between these cultivars contrasting in their sensitivity to chilling will provide new insight into important mechanisms and processes related to resistance against low temperature stress. Moreover, the outcomes of this study will be the basis for future studies aimed to identify markers involved in cold tolerance, which will surely improve the breeding programs of this crop.

\section{Methods \\ Plant material and postharvest treatments}

The commercial zucchini hybrids Natura (Enza Zaden) and Sinatra (Clause-Tezier) were grown under the same greenhouse condition in Almeria, Spain (FEMAGO S.L.). After harvest, fruits of each cultivar were stored in chambers at $4{ }^{\circ} \mathrm{C}$ and $20{ }^{\circ} \mathrm{C}$ during 14 days. Fruits were divided into three replicates per cultivar and storage period ( 0 and 14 days), each consisting in 6 fruits of similar size. After storage, weight loss, electrolyte leakage, and chilling injury-index were measured, and the exocarp tissue of each replicate was frozen in liquid nitrogen and stored at $-80^{\circ} \mathrm{C}$.

\section{Weight loss and chilling-injury index}

The percentage of weight loss of each fruit was calculated as: $\%$ weight loss $=\left(\mathrm{W}_{\mathrm{i}}-\mathrm{W}_{\mathrm{f}}\right) / \mathrm{W}_{\mathrm{i}} \times 100$, being $\mathrm{W}_{\mathrm{i}}$ the initial fruit weight and $\mathrm{W}_{\mathrm{f}}$ the final fruit weight. Chilling injury index of the fruit surface was evaluated in fruit stored at $4{ }^{\circ} \mathrm{C}$ using a subjective scale of visual symptoms previously described [1]: $0=$ no pitting, $1=$ slight $(10 \%$ or less), $2=$ medium $(10-20 \%)$, and $3=$ severe pitting $(>20 \%)$. CI index was determined using the following formula: $\Sigma$ (pitting scale $(0-3) \times$ number of corresponding fruit within each class)/total number of fruit estimated.

\section{Electrolyte leakage}

Electrolyte leakage was measured as described [14]. Briefly, exocarp of zucchini fruit was separated with a vegetable peeler and 10 discs were taken from each replicate with an $11 \mathrm{~mm}$ diameter stainless steel cork borer. Each replicate was rinsed with $50 \mathrm{~mL}$ of deionized water three times for $3 \mathrm{~min}$. After being incubated for $30 \mathrm{~min}$ and shaken at $100 \mathrm{rpm}$ in $50 \mathrm{~mL}$ of deionized water, this solution was measured for conductivity at room temperature using a conductimeter (Consort C860 provided with a conductivity electrode Consort SK10T, Consort nv, Belgium). Total conductivity was determined after boiling the flasks for $10 \mathrm{~min}$ and cooling at room temperature. The electrolyte leakage was expressed as percentage of total conductivity.

\section{Measurement of lipid peroxidation}

Lipid peroxidation was determined as malondialdehyde (MDA) content using the procedure previously described [15], with some modifications. Exocarp ground in liquid nitrogen was homogenized $(1: 4, w / v)$ in $20 \%$ $(\mathrm{w} / \mathrm{v})$ trichloroacetic acid (TCA) and butylated hydroxytoluene was added to a final concentration of $0.67 \%$. The homogenate was centrifuged at $4{ }^{\circ} \mathrm{C}$ and $10,000 \times \mathrm{g}$ for 
15 min. The supernatant was mixed with $0.5 \%(\mathrm{w} / \mathrm{v})$ thiobarbituric acid (TBA) in 20\% TCA in proportion 1:4 $(v / v)$. The mixture was heated at $95{ }^{\circ} \mathrm{C}$ in a water bath for $30 \mathrm{~min}$, cooled immediately in ice to stop the reaction, and centrifuged at $4{ }^{\circ} \mathrm{C}$ and $4000 \times \mathrm{g}$ for $10 \mathrm{~min}$. $\mathrm{Ab}$ sorbance of supernatant was measured at 532 and $600 \mathrm{~nm}$. MDA content was calculated by subtracting the non-specific absorption at $600 \mathrm{~nm}$ from the absorption at $532 \mathrm{~nm}$ and using a standard curve. Results were expressed as nmol MDA g ${ }^{-1}$ of fresh weight.

\section{Determination of $\mathrm{H}_{2} \mathrm{O}_{2}$ content}

$\mathrm{H}_{2} \mathrm{O}_{2}$ content was assayed as described [16]. Zucchini exocarp was ground in liquid nitrogen and homogenized with $0.1 \%(w / v)$ TCA $(1: 4, w / v)$. After centrifugation at $4{ }^{\circ} \mathrm{C}$ and $12,000 \times \mathrm{g}$ for $15 \mathrm{~min}$, the supernatant was collected. The reaction mixture consisted of $0.25 \mathrm{~mL}$ supernatant, $0.25 \mathrm{~mL} 100 \mathrm{mM}$ potassium phosphate buffer ( $\mathrm{pH} 7$ ) and $1 \mathrm{~mL} 1 \mathrm{M}$ KI. The reaction was developed for $1 \mathrm{~h}$ in darkness and the absorbance measured at $390 \mathrm{~nm}$. The amount of $\mathrm{H}_{2} \mathrm{O}_{2}$ was calculated using a standard curve and expressed as $\mu \mathrm{mol} \mathrm{H}_{2} \mathrm{O}_{2} \mathrm{~g}^{-1}$ of fresh weight.

\section{RNA extraction}

Total RNA was extracted from the exocarp of 6 fruits for each replicate as reported [17], treated with RNAseFree DNAse and purified using RNasy MiniElute $^{\mathrm{Tn}}$ Cleanup columns (Qiagen, Hilden, Germany). The quality and quantity of RNA was determined by agarose gel electrophoresis and NanoDrop Lite spectrophotometer (Thermo Fisher Scientific, MA, USA).

Sequencing data processing and gene expression analysis RNA samples were sequenced using Illumina Hiseq2000 at Boyce Thompson Institute (Ithaca, NY, USA). The quality of the single reads generated by Illumina was checked using FastQC (http://www.bioinformatics.babraham.ac.uk/projects/fastqc/). In order to obtain highquality data, the raw reads were pre-processed and trimmed using the software NGS_CRUMBS (https:// bioinf.comav.upv.es/ngs_crumbs/). Through the different utilities the adapters used during the sequencing process were removed, as well as low quality sequences with a Phred quality score $\mathrm{Q}<20$ and ambiguous sequences with $\mathrm{N}$. Using bowtie2 [18], the high quality reads were mapped against Cucurbita pepo transcriptome v3.0 which is included in the genome version 4.1 but was not available when this study was performed [19]. The expression levels were calculated and normalized by the FPKM method with RSEM [20]. Differential expression transcripts were identified using DESeq2 package [21] of the bioconductor package $[22,23]$. Transcripts with an adjusted padj ( $p$-value adjusted for multiple comparisons using Bejamini-Hochberg method) $<0.05$ and a $\log 2$ fold change $(\mathrm{FC}) \pm 1.5$ based in three biological replicates were considered as DEGs. Principal component and clustering analysis were performed with Mev software [24].

\section{Gene ontology (GO) terms enrichment analysis}

BlastoGO software (v2.8.0) [25] was used for GO term differential analysis using the Cucurbita pepo transcriptome v3.0 GO annotation which contains 24,402 annotated unigenes. GO terms enrichment for each data set was calculated by a binomial test model with FDR cut off of 0.05 .

\section{Gene expression analysis by qRT-PCR for RNA-Seq validation}

The expression patterns of 10 random DEGs identified by RNA-Seq in this study were validated by quantitative RT-PCR. Primers pairs for each gene (Additional file 1: Table S1) were designed using Primer3 web tool (http:// bioinfo.ut.ee/primer3-0.4.0/primer3/). Total RNA was extracted as above. First-strand cDNA was synthesized from $1 \mu \mathrm{g}$ total RNA using Maxima Reverse Transcriptase (Thermo Fisher Scientific, Rockford, IL, USA). For qRT-PCR, amplifications were run in a 96-well-plates iCycler iQ thermal cycler (Bio-Rad) using iQ SyBr Green Supermix (BioRad). Quantification was performed with the iCycler iQTM associated software (Real Time Detection System Software, version 2.0). The relative gene expression was calculated using non-stored fruit as the calibration sample. $E F-1 \alpha$ was used as the internal reference gene for normalizing the transcript profiles following the $2^{-\Delta \Delta \mathrm{Ct}}$ method [26].

\section{Statistical analysis}

The experimental design was completely randomized. Data were subjected to analysis of variance (ANOVA) or unpaired t-test using Statgraphics Centurion XVI (Statpoint Technologies, Inc., Warrenton, VA, USA). When appropriate, means were separated by Tukey's HSD test and differences at $p<0.05$ were considered significant.

\section{Results}

Fruit physiological parameters and incidence of chilling injury

Natura and Sinatra fruit were stored at 4 and $20{ }^{\circ} \mathrm{C}$ during 14 days and postharvest quality parameters including percentage of weight loss, CI index, electrolyte leakage, lipid peroxidation (as MDA content), and $\mathrm{H}_{2} \mathrm{O}_{2}$ were recorded (Table 1). Storage at $4{ }^{\circ} \mathrm{C}$ was effective in reducing the fruit weight loss observed in zucchini fruit stored at $20{ }^{\circ} \mathrm{C}$. On the other hand, chilled fruit from Natura and Sinatra showed greater membrane 
Table 1 Changes on quality parameters in chilling-tolerant (Natura) and chilling-sensitive (Sinatra) zucchini fruit stored at $4{ }^{\circ} \mathrm{C}$ and $20{ }^{\circ} \mathrm{C}$ during 14 days

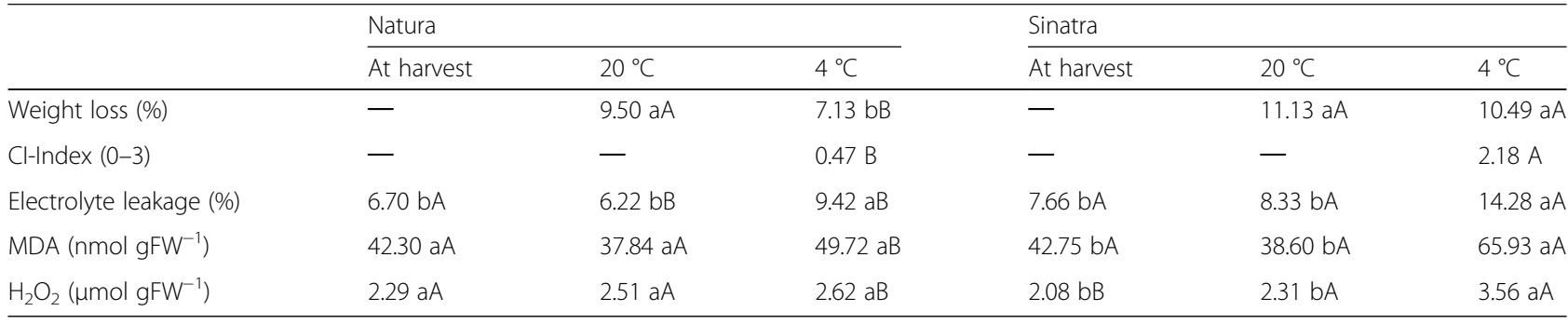

Values are the mean of 3 biological replicates each consisting in 6 fruits. Within each row and cultivar, different lower case letters indicate that means are statistically different $(p<0.05)$ according to Tukey's HSD test (Electro leakage, MDA, and $\mathrm{H}_{2} \mathrm{O}_{2}$ ) or un-paired t-test (Weight loss and Cl). Within each row and temperature, different capital letters indicate that means are statistically different according to un-paired t-test $(p=0.05)$. $C l$ chilling injury, $M D A$ malondialdehyde)

permeability, lipid peroxidation, and $\mathrm{H}_{2} \mathrm{O}_{2}$ content than non-chilled fruit, which presented values similar to fresh harvested fruit in both cultivars. In spite of the clear effect of chilling, the extent of the changes on quality parameters was more pronounced in Sinatra than in Natura. Our data confirmed that cold-stored Sinatra fruit had a greater loss of quality, showing higher weight loss, CI index, electrolyte leakage, lipid peroxidation, and $\mathrm{H}_{2} \mathrm{O}_{2}$ content than Natura fruit.

\section{Differential gene expression in the cold stored fruit of the two cultivars}

The molecular network regulating zucchini fruit response to chilling was studied by performing a RNA-Seq analysis from exocarp of Natura and Sinatra fruit before and after 14 days of storage at $4{ }^{\circ} \mathrm{C}$ and $20{ }^{\circ} \mathrm{C}$. A total of 146 million single reads with an average of 8.1 million reads per sample were generated by Illumina Hiseq2000. After pre-processing and trimming, 133.4 million high quality reads were obtained (an average of 7,412,696 per sample) (Additional file 2: Table S2) and mapped against Cucurbita pepo transcriptome v3.0 [19]. To analyze the complexity of the transcriptomic data and to cluster samples according to their gene expression profile, we first performed a principal component analysis (PCA) over the expression data of the 18 biological samples (Fig. 1). The analysis showed that in all conditions the gene expression profile of the three independent biological replicates clustered together; thus the experiment was considered reliable for further analysis. Furthermore, the PCA revealed that at harvest both cultivars presented a different gene expression pattern. Within each cultivar, fresh-harvested fruit clustered away from stored fruit in $\mathrm{PC} 1$, which explains $42.9 \%$ of the variation. On the other hand, the differences between $4{ }^{\circ} \mathrm{C}$ and $20{ }^{\circ} \mathrm{C}$ stored fruit in Sinatra are explained by both, PC1 and PC2 (38\% of the variation). Interestingly, the changes in the gene expression pattern between Natura chilled and non-chilled fruit were smaller, clustering close together with little separation in either axes.
Gene expression was compared using a pairwise analysis. The comparison of the transcriptome of Natura and Sinatra fruit at harvest (Natura FH/Sinatra FH) revealed 503 DEGs, 262 of which were up-regulated and 241 down-regulated in Natura versus Sinatra (Table 2). The changes in the transcriptomic profiles of the two cultivars were then identified by comparing gene expression values in $4{ }^{\circ} \mathrm{C}$ and $20{ }^{\circ} \mathrm{C}$ stored fruit (cold-stored/ control) in each cultivar independently (Table 2). In Natura, there were 5636 DEGs in cold-stored fruit, from which 2522 were up-regulated (45\%) and 3114 downregulated (55\%). Similarly, in cold-stored fruit of Sinatra there were 6623 DEGs, of which 2845 genes were upregulated (43\%) and 3778 genes were down-regulated (57\%). To validate the results of transcriptomic profiling, the expression of 10 DEGs was analyzed by quantitative RT-PCR. Linear regression analysis was conducted using

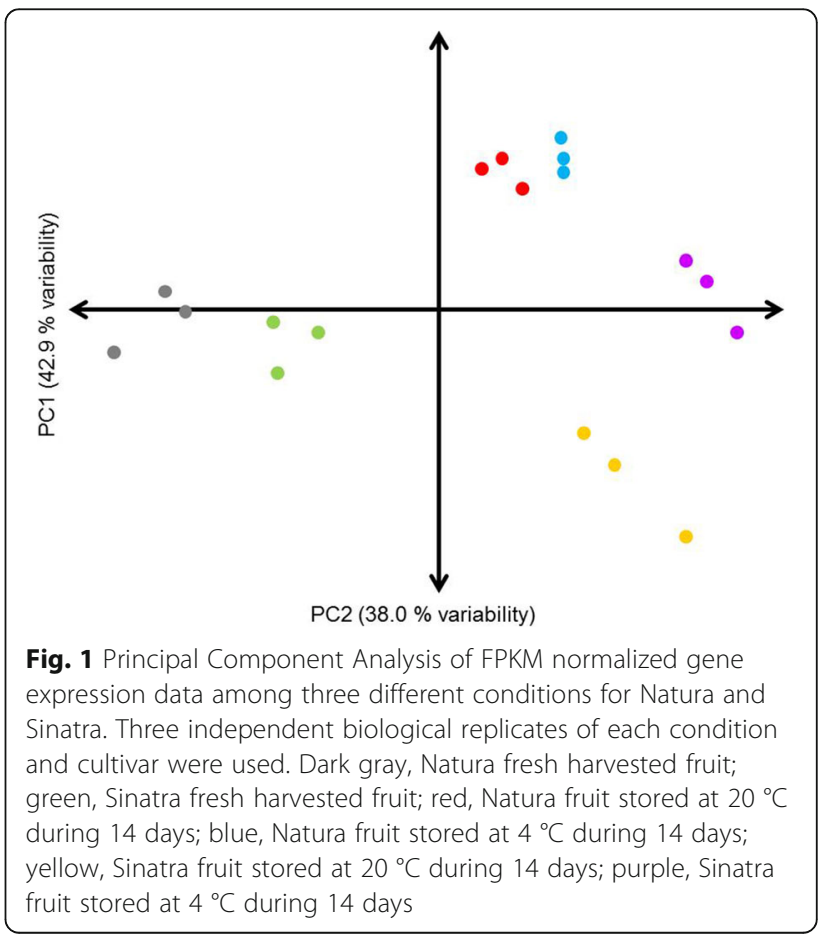


Table 2 Transcriptome profiles in Natura and Sinatra fruit exocarp before and after 14 days of storage at $4{ }^{\circ} \mathrm{C}$ or $20^{\circ} \mathrm{C}$

\begin{tabular}{lllll}
\hline & & \multicolumn{3}{l}{ Differentially expressed genes } \\
\hline Cultivar & Pairwise comparison & Up-regulated & Down-regulated & Total \\
& Natura FH/Sinatra FH & 262 & 241 & 503 \\
\multirow{5}{*}{ Natura } & CS/Control & 2522 & 3114 & 5636 \\
& SS/FH & 2490 & 3753 & 6243 \\
& CS/Control & 2845 & 3778 & 6623 \\
& CS/FH & 2634 & 3530 & 6164 \\
\hline
\end{tabular}

FH fresh harvested fruit, $C S$ fruit stored at $4{ }^{\circ} \mathrm{C}$ during 14 days, Control, fruit stored at $20^{\circ} \mathrm{C}$ during 14 days

Log2 fold change obtained by each approach (Additional file 3: Figure S1). Results showed a significant positive correlation between both methods $\left(R^{2}=0.956\right)$, thus validating the transcriptomic results obtained by RNASeq.

DEGs of each cultivar were compared using a Venn diagram to identify specific genes related to cold tolerance or sensitivity (Fig. 2). Results showed that 2682 DEGs were specific to Natura and 3669 were specific to Sinatra. Regarding up-regulated DEGs, 1221 were specific of Natura and 1568 were exclusively identified in Sinatra ( $45 \%$ and $43 \%$ respectively). Down-regulated genes differentially regulated in Natura were 1461; while in the case of Sinatra, 2101 were specific, representing $54 \%$ and $57 \%$ of the DEGs in each cultivar, respectively. The percentage of specific DEGs induced and repressed in response to chilling was similar in both cultivars. On the other hand, Natura and Sinatra shared 2954 DEGs, from which 1264 were induced (43\%) and 1640 were down-regulated (55\%) in both cultivars. Moreover, there was a group of common DEGs showing opposite cold-

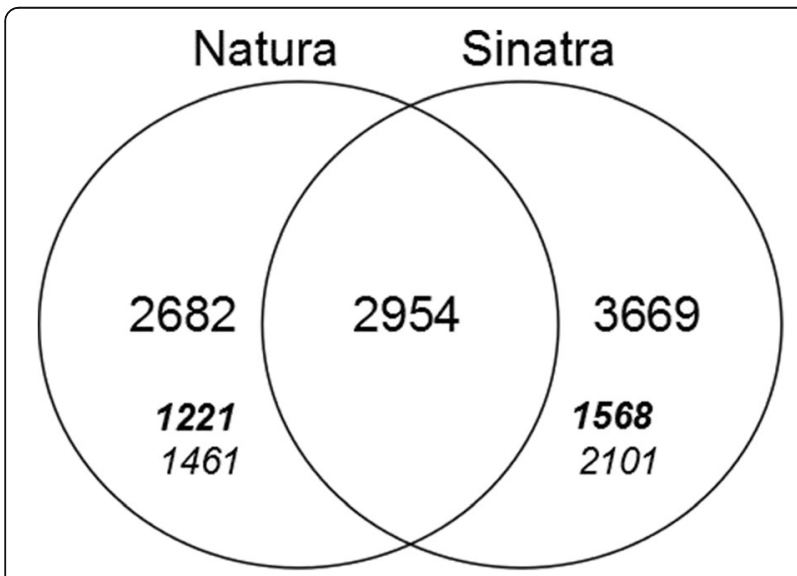

Fig. 2 Venn diagram of the differentially expressed genes in fruit from Natura and Sinatra exposed to cold storage $\left(4^{\circ} \mathrm{C}\right.$ vs $\left.20^{\circ} \mathrm{C}\right)$. Bold-italic numbers depict the DEGs specifically up-regulated due to cold storage in each cultivar. Italic numbers depict the DEGs specifically down-regulated due to cold storage in each cultivar specific regulation, i.e. 37 DEGs were up-regulated in Natura and down-regulated in Sinatra, while 13 DEGs were repressed in Natura and induced in Sinatra. The complete list of specific and common cold-regulated genes as well as those found differentially expressed between cultivars at harvest is available in Additional file 4: Table S3.

\section{Functional analysis of the differential gene expression in fruit of the two cultivars}

To explore the biological functions of the cold-induced and repressed DEGs of each cultivar, a gene ontology (GO) enrichment analysis was conducted. Overrepresentation of GO terms was evaluated to correlate different biological processes (BPs), molecular functions (MFs), and cellular components (CCs) with cultivar-dependent chilling response in the exocarp of zucchini fruit.

\section{Functional analysis of the differential gene expression in fruit of the two cultivars before storage}

Regarding the comparison between Natura and Sinatra fruit at harvest, $5 \mathrm{GO}$ categories (4 BPs and $1 \mathrm{CC}$ ) were up-regulated and 3 (2 BPs and $1 \mathrm{MF}$ ) were downregulated in Natura compared to Sinatra. The BPs represented by the largest number of DEGs up-regulated in Natura fruit compared to Sinatra fruit before storage were 'response to oxidative stress', 'response to cold' and 'fatty acid biosynthetic process', while the three GO categories down-regulated in these fruit were the BPs 'Glycoxylate metabolic process' and 'glycoxylate cycle' and the MF 'Isocitrate lyase activity' (Fig. 3, Additional file 5: Table S4).

\section{Functional analysis of the differential gene expression in cold-stored fruit of the two cultivars}

Figure 4 shows the overrepresented GO terms in DEGs that were specific for the cold tolerant cv. Natura or for the cold-sensitive cv. Sinatra, and in DEGs that were common to both cultivars. In Natura-specific upregulated DEGs several GO terms were found that belong to abiotic- and biotic-stress responses (16\% of up-regulated DEGs) such as response to 'metal ion,' 'salt stress', 'temperature stimulus', and 'defense response to bacterium' (Fig. 4a). Interestingly, three BPs upregulated in Natura, i.e. 'response to misfolded protein', 'proteasome core complex assembly', and 'proteasomal ubiquitin-dependent protein catabolic processes', were related to proteolysis (Additional file 6: Table S5). Other BPs overrepresented in Natura were 'glycolysis', 'toxin catabolic process', and 'hydrogen peroxide catabolic process'. The functional analysis of up-regulated DEGs in Natura also revealed that the largest MF categories in this cultivar were 'threonine-type endopeptidase activity', 'transferase activity', and 'protein domain specific 


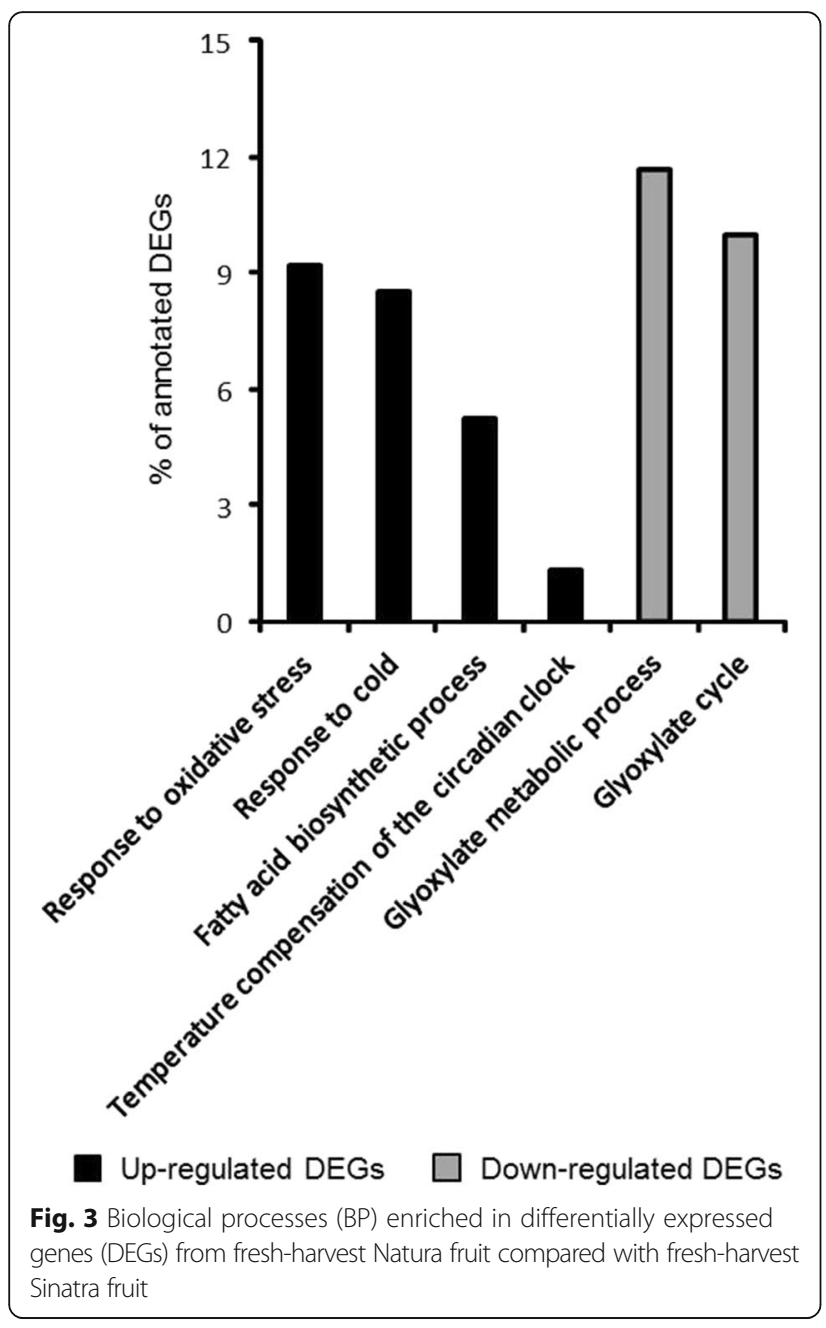

binding' (Additional file 7: Figure S2A), while 'cytosol', 'chloroplast stroma', and chloroplast envelope' were the CCs represented with the largest number of DEGs (Additional file 8: Figure S3A). On the other hand, only two enriched GO terms resulted from the functional analysis of down-regulated DEGs specific of Natura. These GO terms were the BP 'meristem maintenance' and the CC 'cell periphery' (Fig. 4a and Additional file 8: Figure S3). The former is integrated by DEGs that control the expression of the meristem genes and regulates the response to hormones such as auxins, while the latter includes DEGs whose function are expressed in plasma membrane or cell wall.

The functional analysis of cold response in Sinatra fruit revealed that there were no overrepresented GO terms in upregulated genes, while there were many terms overrepresented in cold-repressed DEGs (Additional file 9: Table S6). Regarding BPs, $21 \%$ of down-regulated DEGs in Sinatra were represented in GO terms related to exposure to biotic and abiotic stress conditions such as 'defense response to other organism,' 'response to salt stress', 'response to cadmium ion,' 'response to cold,' 'response to abscisic acid stimulus', 'response to wounding', and 'response to water deprivation' (Fig. 4b). The MFs more overrepresented in down-regulated DEGs were related to ion binding (Additional file 7: Figure S2B) and the largest CCs were the 'plasma membrane', 'plasmodesma', and 'chloroplast thylakoid membrane' (Additional file 8: Figure S3B).

Up-regulated transcripts common to both cultivars were only enriched in three BPs; 'cellular response to nutrient levels', 'heat acclimation', and 'negative regulation of endopeptidase activity' (Fig. 4c). The most overrepresented MFs were related to oxidation-reduction reactions, 'monooxygenase activity', and 'oxidoreductase activity' (Additional file 7: Figure S2C). On the other hand, the functional analysis of cold-repressed DEGs common to both cultivars (Fig. 4c, Additional file 10: Table S7) revealed that most of the overrepresented BPs were related to response to several stimuli ('response to hormone stimulus,' 'response to other organism', and 'response to osmotic stress'), cell wall and cuticle biosynthesis ('pectin metabolic process', 'cuticle development', and 'wax biosynthetic process'), and photosynthesis and exposition to light ('photosynthesis, and light harvesting', 'non-photochemical quenching' and 'anthocyanin accumulation in tissues in response to UV light'). The largest MF in down-regulated DEGs from both cultivars was 'transferase activity' (Additional file 7: Figure S2C) and the CCs were 'plastid envelope,' 'apoplast', and 'plant-type cell wall' (Additional file 8: Figure S3C).

\section{Transcription factors}

Around 289 and 314 DE transcription factor (TF) genes were identified in Natura and Sinatra fruit, respectively, when $4{ }^{\circ} \mathrm{C}$ and $20{ }^{\circ} \mathrm{C}$ stored fruit of each cultivar was compared (Additional file 4: Table S3). From these, 47 and 60 were specifically up and down-regulated in Natura respectively; most of them belonged to the zinc finger, NAC, and MYB families. With respect to the cold-sensitive Sinatra, the number of specific downregulated TFs was much larger (96) than the upregulated ones (30) and they were part of the zinc finger, WRKY, and AP2/EREBP (including ERFs and CBF/ DREBs) families. From these DE TF genes, those belonging to overrepresented BPs identified in our functional analysis are listed in Table 3.

\section{Putative candidate genes for cold tolerance in zucchini fruit}

In order to identify genes more likely to be related to acquisition of chilling tolerance in zucchini, a careful analysis of all DEGs in our dataset was carried out. The selected genes were those showing a differential expression pattern between Natura and Sinatra and 


\section{a}
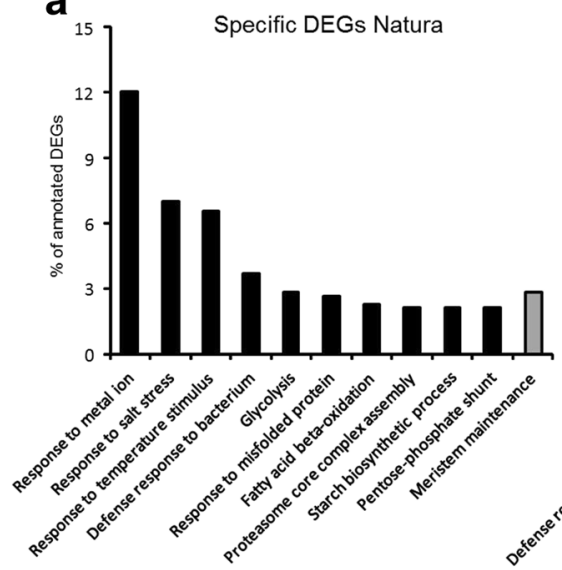

C

${ }^{15}$ Common DEGs
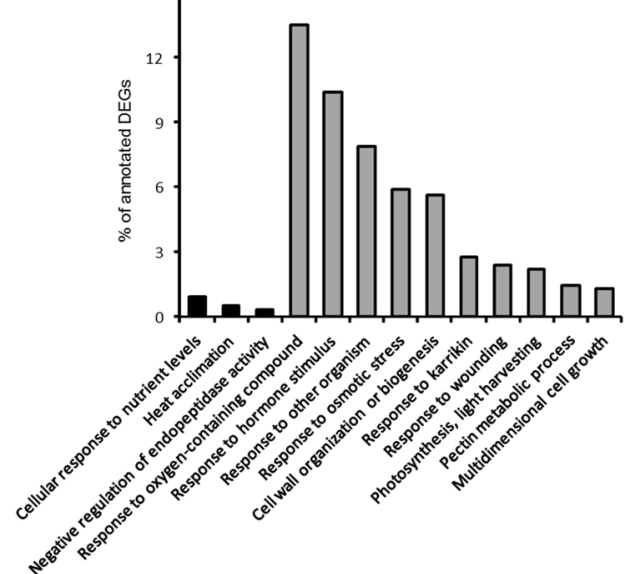

b

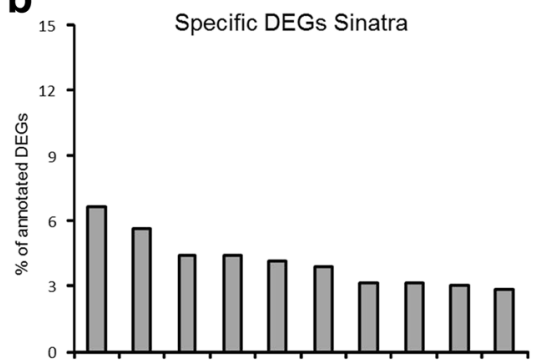

.

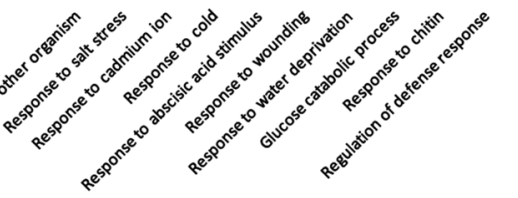

U Up-regulated DEGs $\square$ Down-regulated DEGs

Fig. 4 Most enriched biological processes (BP) in percentage of differentially expressed genes (DEGs) specific to Natura (a), specific to Sinatra (b), or common in both cultivars (c) exposed to cold storage $\left(4{ }^{\circ} \mathrm{C}\right.$ vs $\left.20^{\circ} \mathrm{C}\right)$

were differentially expressed in cold-stored fruit compared to fruit stored at $20{ }^{\circ} \mathrm{C}$ and/or compared to freshly-harvested fruit. The selected candidate genes were grouped according to the following metabolic pathways: carbohydrate and energy metabolism, lipid metabolism, peptide transport, transcription, and signal transduction (Table 4). Their expression patterns and their possible role in cold-tolerance in zucchini fruit will be discussed below.

\section{Discussion}

Zucchini fruit is known to be sensitive to cold storage; although the degree of chilling susceptibility is very dependent on the cultivar $[6,9]$. Present fruit quality parameters in Natura and Sinatra fruit after cold storage confirmed previous reports indicating that chilling affects the fruit of the two cultivars, although Natura fruit were more tolerant to chilling and withstood cold better than Sinatra fruit. Furthermore, the chilling tolerance induced by diverse postharvest treatments, including preconditioning at moderate temperature before cold storage [12] or individual shrink wrapping [11], correlates with a better fruit antioxidant status. However, a holistic overview of the molecular bases of the zucchini response to chilling is still lacking.

\section{Transcriptional bases for the differential response of fruit of the two zucchini cultivars to cold storage}

The PCA analysis showed a differential transcriptomic response between cultivars; Sinatra fruit stored at $20{ }^{\circ} \mathrm{C}$ were clustered away from fruit stored at $4^{\circ}$ $\mathrm{C}$, whereas chilled and non-chilled fruit from Natura were grouped together. Likewise, the number of DEGs in cold-stored fruit compared to fruit stored at $20{ }^{\circ} \mathrm{C}$ was higher in cv. Sinatra than in cv. Natura. This result suggests larger transcriptomic changes in the cold-sensitive Sinatra after cold storage. On the other hand, 2954 DEGs were shared among Sinatra and Natura, reflecting that some of the chilling responses to cold storage are common 
Table 3 Expression profile (FPKM) of transcription factors obtained in the functional analysis of differentially expressed genes from Natura and Sinatra fruit before (fresh harvested, FH) and after 14 days of storage at $20{ }^{\circ} \mathrm{C}$ and $4{ }^{\circ} \mathrm{C}$

\begin{tabular}{|c|c|c|c|c|c|c|c|c|}
\hline \multirow[t]{2}{*}{ TF family } & \multirow[t]{2}{*}{ ID } & \multirow[t]{2}{*}{ Description } & \multicolumn{3}{|l|}{ Natura } & \multicolumn{3}{|l|}{ Sinatra } \\
\hline & & & $\mathrm{FH}$ & $20^{\circ} \mathrm{C}$ & $4^{\circ} \mathrm{C}$ & $\mathrm{FH}$ & $20^{\circ} \mathrm{C}$ & $4^{\circ} \mathrm{C}$ \\
\hline \multirow[t]{22}{*}{ MYB } & CUUC76408 & Transcription factor MYB3-like & 3.66 & 3.51 & 16.73 & 7.48 & 11.55 & 78.99 \\
\hline & CUUC60565 & Transcription factor MYB21-like & 67.90 & 2.01 & 79.86 & 63.86 & 0.97 & 88.15 \\
\hline & CUUC61101 & MYB-like transcription factor & 0.56 & 1.97 & 27.34 & 0.58 & 0.49 & 13.62 \\
\hline & CUUC107223 & MYB transcription factor & 43.98 & 16.70 & 4.35 & 35.69 & 27.19 & 7.48 \\
\hline & CUUC92574 & MYB transcription factor & 27.24 & 10.09 & 0.96 & 62.02 & 44.99 & 0.65 \\
\hline & CUUC105130 & MYB transcription factor & 0.55 & 9.12 & 0.28 & 2.64 & 49.64 & 0.63 \\
\hline & CUUC114817 & MYB transcription factor MYB6-like & 15.93 & 128.73 & 2.10 & 19.16 & 42.95 & 3.15 \\
\hline & CUUC114902 & Transcription factor MYB21-like & 27.37 & 11.41 & 0.29 & 21.23 & 7.16 & 0.25 \\
\hline & CUUC99695 & Transcription factor MYB44-like & 109.74 & 164.22 & 28.68 & 168.20 & 642.78 & 21.07 \\
\hline & CUUC100605 & Transcription factor MYB44-like & 12.21 & 57.39 & 5.90 & 27.76 & 61.65 & 4.84 \\
\hline & CUUC96330 & Transcription factor MYB44-like & 9.40 & 14.13 & 0.83 & 24.65 & 65.87 & 0.83 \\
\hline & CUUC100606 & Transcription factor MYB44-like & 33.63 & 214.78 & 17.02 & 65.88 & 171.28 & 21.33 \\
\hline & CUUC100844 & Transcription factor MYB86-like & 212.66 & 70.42 & 15.06 & 89.09 & 42.66 & 8.88 \\
\hline & CUUC61032 & MYB-like transcription factor 1 & 9.91 & 14.79 & 2.41 & 2.90 & 10.70 & 2.62 \\
\hline & CUUC88157 & MYB-related protein 315-like & 42.22 & 6.72 & 0.09 & 23.19 & 2.69 & 0.20 \\
\hline & CUUC62256 & MYB-related protein 306-like & 16.92 & 20.38 & 6.74 & 19.27 & 49.50 & 0.82 \\
\hline & CUUC91200 & MYB-related protein 306-like & 165.85 & 202.64 & 48.94 & 86.80 & 134.76 & 40.70 \\
\hline & CUUC97744 & MYB-related protein 308-like & 17.43 & 11.96 & 1.80 & 8.88 & 11.43 & 1.74 \\
\hline & CUUC90701 & Transcription repressor MYB6 & 49.44 & 78.17 & 12.15 & 18.50 & 78.11 & 8.59 \\
\hline & CUUC104651 & Transcription factor MYB1R1-like & 4.07 & 5.66 & 6.33 & 10.71 & 49.89 & 2.45 \\
\hline & CUUC107116 & Transcription factor MYB1R1-like & 271.52 & 71.70 & 204.51 & 281.76 & 92.69 & 170.24 \\
\hline & CUUC97743 & Transcription factor MYB76-like & 0.37 & 0.16 & 61.85 & 0.00 & 0.04 & 0.00 \\
\hline \multirow[t]{4}{*}{ MYC } & CUUC104046 & Transcription factor MYC2-like & 19.01 & 52.12 & 13.70 & 27.43 & 34.69 & 10.84 \\
\hline & CUUC97393 & Transcription factor MYC2-like & 0.00 & 1.65 & 1.49 & 0.00 & 5.43 & 0.00 \\
\hline & CUUC97395 & Transcription factor MYC2-like & 0.62 & 4.07 & 3.42 & 1.06 & 11.91 & 1.87 \\
\hline & CUUC97396 & Transcription factor MYC2-like & 1.63 & 15.37 & 6.45 & 3.73 & 34.58 & 3.20 \\
\hline \multirow[t]{15}{*}{ AP2/EREBP } & CUUC85063 & Ethylene-responsive element binding protein (RAP2.3) & 6.83 & 4.75 & 40.84 & 11.00 & 21.25 & 93.89 \\
\hline & CUUC104934 & AP2/ERF domain-containing transcription factor & 13.54 & 8.61 & 144.59 & 20.40 & 171.93 & 55.08 \\
\hline & CUUC92545 & Floral homeotic protein APETALA 2-like & 8.78 & 8.18 & 1.94 & 10.96 & 4.75 & 2.41 \\
\hline & CUUC60589 & Ethylene-responsive transcription factor 1a-like & 19.45 & 74.32 & 11.80 & 36.44 & 232.63 & 10.58 \\
\hline & CUUC60504 & Ethylene-responsive transcription factor 3-like & 46.24 & 156.62 & 37.86 & 75.04 & 564.86 & 24.47 \\
\hline & CUUC80448 & Ethylene-responsive transcription factor 4-like & 4.51 & 21.21 & 0.84 & 21.32 & 318.13 & 0.38 \\
\hline & CUUC80117 & Ethylene-responsive transcription factor ABR1-like & 1.72 & 9.76 & 0.00 & 0.78 & 100.83 & 0.10 \\
\hline & CUUC86480 & Ethylene-responsive transcription factor ERF025-like & 1.00 & 2.79 & 0.14 & 1.75 & 69.38 & 0.00 \\
\hline & CUUC60600 & Ethylene-responsive transcription factor ERF061-like & 10.21 & 6.20 & 0.12 & 9.39 & 40.49 & 0.11 \\
\hline & CUUC113307 & Ethylene-responsive transciptional coactivator-like protein & 6.14 & 41.76 & 13.51 & 2.45 & 12.01 & 3.73 \\
\hline & CUUC85491 & Ethylene-responsive transcription factor 4-like & 54.18 & 10.44 & 14.05 & 105.17 & 57.68 & 2.81 \\
\hline & CUUC100239 & Ethylene-responsive transcription factor 5-like & 144.65 & 269.58 & 104.81 & 144.26 & 264.43 & 60.98 \\
\hline & CUUC128676 & Ethylene-responsive transcription factor ERF025-like & 0.00 & 0.61 & 0.00 & 0.00 & 34.17 & 0.00 \\
\hline & CUUC67060 & Ethylene-responsive transcription factor ERF098-like & 2.43 & 4.96 & 4.16 & 3.55 & 17.70 & 2.29 \\
\hline & CUUC92773 & C-repeat binding factor & 14.79 & 14.92 & 15.58 & 17.02 & 329.14 & 2.41 \\
\hline WRKY & CUUC78817 & WRKY transcription factor & 64.33 & 32.44 & 0.12 & 21.16 & 85.43 & 0.21 \\
\hline
\end{tabular}


Table 3 Expression profile (FPKM) of transcription factors obtained in the functional analysis of differentially expressed genes from Natura and Sinatra fruit before (fresh harvested, FH) and after 14 days of storage at $20{ }^{\circ} \mathrm{C}$ and $4{ }^{\circ} \mathrm{C}$ (Continued)

\begin{tabular}{|c|c|c|c|c|c|c|c|c|}
\hline \multirow[t]{2}{*}{ TF family } & \multirow[t]{2}{*}{ ID } & \multirow[t]{2}{*}{ Description } & \multicolumn{3}{|l|}{ Natura } & \multicolumn{3}{|l|}{ Sinatra } \\
\hline & & & $\overline{\mathrm{FH}}$ & $20^{\circ} \mathrm{C}$ & $4^{\circ} \mathrm{C}$ & $\overline{\mathrm{FH}}$ & $20^{\circ} \mathrm{C}$ & $4^{\circ} \mathrm{C}$ \\
\hline & CUUC78015 & WRKY transcription factor 11 & 9.14 & 39.95 & 12.08 & 8.13 & 423.96 & 2.12 \\
\hline & CUUC109151 & Probabl WRKY transcription factor 57-like & 153.19 & 176.78 & 13.09 & 135.11 & 110.75 & 13.70 \\
\hline & CUUC80636 & WRKY transcription factor 11 & 7.99 & 12.59 & 12.15 & 9.14 & 71.52 & 3.25 \\
\hline & CUUC101660 & WRKY transcription factor 11 & 91.93 & 89.85 & 47.91 & 70.93 & 194.23 & 12.40 \\
\hline & CUUC98190 & Probable WRKY transcription factor 15 -like & 6.36 & 7.38 & 3.09 & 6.81 & 15.78 & 1.95 \\
\hline & CUUC95930 & Probable WRKY transcription factor 40-like & 16.60 & 50.80 & 24.11 & 73.23 & 756.56 & 10.15 \\
\hline & CUUC99636 & Probable WRKY transcription factor 48-like & 24.91 & 28.80 & 90.78 & 17.46 & 53.54 & 41.51 \\
\hline \multirow[t]{9}{*}{ Zinc finger } & CUUC63321 & Zinc finger protein 6-like & 4.03 & 0.07 & 39.31 & 2.08 & 0.24 & 11.48 \\
\hline & CUUC61049 & Zinc finger protein zat10-like & 396.63 & 148.71 & 1436.86 & 501.20 & 1727.79 & 509.51 \\
\hline & CUUC99174 & DOF zinc finger & 0.11 & 11.64 & 0.27 & 0.34 & 80.45 & 0.21 \\
\hline & CUUC98221 & Zinc finger protein & 15.27 & 41.14 & 13.03 & 12.66 & 20.12 & 5.73 \\
\hline & CUUC96411 & Zinc finger protein & 11.38 & 16.64 & 1.53 & 19.49 & 78.29 & 2.59 \\
\hline & CUUC62446 & $\begin{array}{l}\text { Zinc finger A20 and AN1 domain-containing } \\
\text { stress-associated protein 8-like }\end{array}$ & 795.38 & 1812.88 & 84.14 & 402.13 & 200.91 & 59.30 \\
\hline & CUUC114244 & Zinc finger protein constans-like 16 -like & 136.78 & 22.13 & 0.91 & 114.19 & 47.78 & 1.13 \\
\hline & CUUC90956 & DOF zinc finger & 30.54 & 7.16 & 7.94 & 10.04 & 7.48 & 1.68 \\
\hline & CUUC99589 & $\begin{array}{l}\text { Zinc finger A20 and AN1 domain-containing } \\
\text { stress-associated protein 5-like }\end{array}$ & 167.88 & 264.77 & 204.49 & 146.95 & 600.31 & 101.75 \\
\hline \multirow[t]{11}{*}{ Zinc finger } & CUUC94374 & Zinc finger protein constans-like 5 -like & 101.80 & 54.60 & 33.48 & 112.14 & 122.61 & 29.87 \\
\hline & CUUC82499 & Zinc finger protein ZAT10-like & 0.64 & 6.27 & 2.85 & 1.18 & 12.34 & 2.68 \\
\hline & CUUC110378 & NF-X1-type zinc finger protein NFXL1 & 8.57 & 8.57 & 5.03 & 8.44 & 14.71 & 3.99 \\
\hline & CUUC111731 & Zinc finger protein 6-like & 0.71 & 0.00 & 29.72 & 0.00 & 0.00 & 1.87 \\
\hline & CUUC90133 & $\begin{array}{l}\text { Zinc finger AN1 domain-containing stress-associated } \\
\text { protein 12-like }\end{array}$ & 13.01 & 23.39 & 127.98 & 16.81 & 70.74 & 68.77 \\
\hline & CUUC115999 & Zinc finger $\mathrm{CCCH}$ domain-containing protein 40-like & 15.88 & 15.96 & 49.68 & 6.82 & 16.31 & 17.54 \\
\hline & CUUC90883 & $\mathrm{CCCH}$-type zinc finger protein & 157.10 & 37.39 & 4.55 & 86.19 & 8.55 & 5.36 \\
\hline & CUUC90884 & Zinc finger $\mathrm{CCCH}$ domain-containing protein 49-like & 465.40 & 98.87 & 14.02 & 240.48 & 17.12 & 10.80 \\
\hline & CUUC90885 & Zinc finger $\mathrm{CCCH}$ domain-containing protein 49-like & 661.73 & 160.02 & 13.39 & 308.34 & 24.90 & 20.43 \\
\hline & CUUC63652 & Zinc finger protein constans-like 9-like & 11.31 & 43.71 & 8.70 & 19.90 & 16.26 & 8.59 \\
\hline & CUUC107974 & Zinc finger protein nutcracker-like & 7.45 & 10.06 & 2.28 & 10.43 & 2.83 & 1.52 \\
\hline \multirow[t]{2}{*}{ GRAS } & CUUC81379 & DELLA protein & 0.82 & 0.68 & 0.28 & 2.70 & 6.44 & 0.07 \\
\hline & CUUC105134 & DELLA protein GAIP & 11.12 & 9.99 & 36.80 & 13.29 & 10.46 & 20.50 \\
\hline \multirow[t]{2}{*}{ HSF } & CUUC120379 & Heat stress transcription factor b-2a-like & 5.38 & 23.54 & 6.75 & 5.67 & 22.41 & 6.49 \\
\hline & CUUC114014 & Heat stress transcription factor $\mathrm{c}-1$-like & 2.22 & 0.00 & 4.14 & 0.87 & 2.10 & 1.83 \\
\hline \multirow{6}{*}{$\begin{array}{l}\text { Homeobox-leucine } \\
\text { zipper }\end{array}$} & CUUC100213 & Homeobox protein ATH1-like & 10.83 & 28.85 & 0.91 & 10.23 & 14.87 & 2.55 \\
\hline & CUUC94869 & Homeobox-leucine zipper protein ATHB-6-like & 6.71 & 34.04 & 0.22 & 4.98 & 20.26 & 2.54 \\
\hline & CUUC94870 & Homeobox-leucine zipper protein ATHB-6-like & 30.21 & 42.74 & 4.06 & 39.53 & 30.61 & 4.67 \\
\hline & CUUC103438 & Homeobox-leucine zipper protein ATHB-7 & 4.30 & 8.57 & 0.55 & 2.19 & 9.27 & 1.27 \\
\hline & CUUC64965 & Homeobox-leucine zipper protein ATHB-13-like & 162.15 & 94.10 & 7.62 & 196.41 & 103.56 & 24.87 \\
\hline & CUUC114435 & Homeobox-leucine zipper protein REVOLUTA-like & 7.02 & 7.87 & 0.45 & 10.72 & 2.76 & 0.23 \\
\hline \multirow[t]{3}{*}{ NAC } & CUUC111022 & NAC domain-containing protein 2-like & 12.90 & 10.53 & 7.26 & 15.12 & 37.27 & 5.11 \\
\hline & CUUC111023 & NAC domain-containing protein 2-like & 44.99 & 65.62 & 39.93 & 52.37 & 341.98 & 35.31 \\
\hline & CUUC127119 & NAC domain-containing protein 7-like & 0.00 & 0.32 & 5.03 & 0.11 & 0.50 & 3.64 \\
\hline
\end{tabular}


Table 3 Expression profile (FPKM) of transcription factors obtained in the functional analysis of differentially expressed genes from Natura and Sinatra fruit before (fresh harvested, FH) and after 14 days of storage at $20{ }^{\circ} \mathrm{C}$ and $4{ }^{\circ} \mathrm{C}$ (Continued)

\begin{tabular}{|c|c|c|c|c|c|c|c|c|}
\hline \multirow[t]{2}{*}{ TF family } & \multirow[t]{2}{*}{ ID } & \multirow[t]{2}{*}{ Description } & \multicolumn{3}{|c|}{ Natura } & \multicolumn{3}{|l|}{ Sinatra } \\
\hline & & & $\mathrm{FH}$ & $20^{\circ} \mathrm{C}$ & $4{ }^{\circ} \mathrm{C}$ & $\mathrm{FH}$ & $20^{\circ} \mathrm{C}$ & $4{ }^{\circ} \mathrm{C}$ \\
\hline Auxin & CUUC79119 & Auxin response factor 18 -like & 3.27 & 8.95 & 0.20 & 2.96 & 6.95 & 0.18 \\
\hline ASG & CUUC104842 & Transcription factor ASG4-like & 68.56 & 64.21 & 5.37 & 50.61 & 23.46 & 7.22 \\
\hline TCP & CUUC114074 & Transcription factor TCP14-like & 15.09 & 29.40 & 6.93 & 31.43 & 22.70 & 5.66 \\
\hline \multirow[t]{2}{*}{ bZIP } & CUUC109603 & bZIP transcription factor 17-like & 12.50 & 24.50 & 37.19 & 12.39 & 69.08 & 19.55 \\
\hline & CUUC105987 & bZIP transcription factor bZIP107 & 3.07 & 4.04 & 0.55 & 5.08 & 4.85 & 0.33 \\
\hline \multirow[t]{2}{*}{ Others } & CUUC100506 & Transcription initiation factor IIB-2 & 24.24 & 33.53 & 16.27 & 31.19 & 44.73 & 13.84 \\
\hline & CUUC100507 & Transcription initiation factor IIB-2 & 7.88 & 27.61 & 12.38 & 7.70 & 53.61 & 6.89 \\
\hline \multirow[t]{3}{*}{ Others } & CUUC95110 & $\begin{array}{l}\text { Probable CRR4-associated factor } \\
1 \text { homolog } 11 \text {-like }\end{array}$ & 57.66 & 76.32 & 89.75 & 80.36 & 547.40 & 32.01 \\
\hline & CUUC90180 & $\begin{array}{l}\text { Probable CRR4-associated factor } \\
1 \text { homolog } 11 \text {-like }\end{array}$ & 87.95 & 242.84 & 192.73 & 145.45 & 1057.13 & 80.70 \\
\hline & CUUC110049 & Transcription factor LHW-like & 60.23 & 115.26 & 25.12 & 135.27 & 81.23 & 35.87 \\
\hline
\end{tabular}

in fruit of both cultivars. In this sense, the ratio of up- and down-regulated genes was also similar in both cultivars, meaning that the number of repressed genes was slightly higher than the number of induced genes. Transcriptomic studies in other species suggest that this ratio of differential gene expression in response to cold may not be related to acclimation but rather to a species dependent response. Thus, in several species such as Arabidopsis thaliana or Camellia sinensis, it has been reported that in response to cold the number of up-

Table 4 Candidate genes likely to be involved in chilling tolerance of zucchini fruit. Expression profile in fruit before (fresh harvested, $\mathrm{FH}$ ) and after 14 days of storage at $20^{\circ} \mathrm{C}$ and $4^{\circ} \mathrm{C}$ is shown in FPKMs

\begin{tabular}{|c|c|c|c|c|c|c|c|}
\hline & & \multicolumn{3}{|l|}{ Natura } & \multicolumn{3}{|l|}{ Sinatra } \\
\hline & & $\mathrm{FH}$ & $20^{\circ} \mathrm{C}$ & $4{ }^{\circ} \mathrm{C}$ & $\mathrm{FH}$ & $20^{\circ} \mathrm{C}$ & $4{ }^{\circ} \mathrm{C}$ \\
\hline \multicolumn{8}{|c|}{ Carbohydrate and Energy Metabolism } \\
\hline CUUC107944 & Malate dehydrogenase & 15.18 & 8.09 & 24.28 & 10.44 & 13.40 & 8.09 \\
\hline \multicolumn{8}{|l|}{ Lipid metabolism } \\
\hline CUUC60795 & $\begin{array}{l}\text { Phosphatidylinositol:ceramide } \\
\text { inositolphosphotransferase 2-like }\end{array}$ & 10.50 & 80.72 & 27.58 & 17.98 & 194.82 & 10.87 \\
\hline \multicolumn{8}{|l|}{ Peptide transport } \\
\hline CUUC107903 & Peptide transporter PTR3-A-like & 53.95 & 47.18 & 279.90 & 35.85 & 57.65 & 91.19 \\
\hline CUUC89270 & Peptide transporter PTR2-like & 9.65 & 5.05 & 32.93 & 8.81 & 7.48 & 16.57 \\
\hline CUUC89268 & Peptide transporter PTR2-like & 2.46 & 1.28 & 10.33 & 2.75 & 1.62 & 4.75 \\
\hline \multicolumn{8}{|l|}{ Transcription } \\
\hline CUUC97743 & Transcription factor MYB76-like & 0.37 & 0.16 & 61.85 & 0.00 & 0.04 & 0.00 \\
\hline CUUC105134 & DELLA protein GAIP & 11.12 & 9.99 & 36.80 & 13.29 & 10.46 & 20.50 \\
\hline CUUC104934 & $\begin{array}{l}\text { AP2 ERF domain-containing } \\
\text { transcription factor }\end{array}$ & 13.54 & 8.61 & 144.59 & 20.40 & 171.93 & 55.08 \\
\hline CUUC92773 & C-repeat binding factor (CBF) & 14.79 & 14.92 & 15.58 & 17.02 & 329.14 & 2.41 \\
\hline CUUC61049 & Zinc finger protein ZAT10-like & 396.63 & 148.71 & 1436.86 & 501.20 & 1727.79 & 509.51 \\
\hline \multicolumn{8}{|c|}{ Signal Transduction } \\
\hline CUUC94909 & 14-3-3 protein & 25.70 & 20.27 & 70.56 & 20.35 & 23.34 & 18.01 \\
\hline CUUC94908 & 14-3-3 protein & 102.54 & 73.32 & 231.82 & 96.27 & 115.22 & 110.64 \\
\hline CUUC94906 & 14-3-3-like protein & 37.59 & 31.54 & 155.09 & 28.02 & 51.27 & 48.98 \\
\hline CUUC94907 & 14-3-3-like protein & 136.59 & 65.48 & 319.09 & 101.46 & 161.40 & 134.28 \\
\hline CUUC111254 & 14-3-3-like protein & 79.77 & 87.18 & 256.54 & 56.72 & 71.25 & 123.10 \\
\hline
\end{tabular}


regulated genes was larger $[27,28]$, whereas in other species such as Populus simonii or Solanum lycopersicum this number was either lower or the same [29,30].

\section{Molecular mechanisms related to chilling tolerance in zucchini fruit}

The functional analysis of DEGs in zucchini fruit before storage revealed that the response to abiotic stresses ('response to cold', 'response to oxidative stress' and 'regulation of the circadian clock by temperature') was up-regulated in Natura fruit when compared to Sinatra. Interestingly, the most overrepresented BPs in cold-induced genes from Natura fruit after cold storage were also those related to abiotic ('response to metal ion', 'response to salt stresses, and 'response to temperature stimulus') and biotic ('defense response to bacterium') responses to stress conditions. On the other hand, in the sensitive cultivar Sinatra, BPs related to biotic ('defense response to other organism') and abiotic ('response to salt stress', 'response to cadmium ion', 'response to cold', 'response to abscisic acid stimulus', 'response to wounding', and 'response to water deprivation') stresses were also overrepresented but the genes were down-regulated. Our data suggest that this differential regulation may be related to the degree of sensitivity of zucchini fruit cultivars to low temperature and may be fundamental in preventing the negative effect of cold storage in the more chilling-tolerant cultivar. Furthermore, our results support previous reports showing a cross-talk between different stresses, as is the case of cassava apical shoots [31], asparagus bean seedlings [32], and table grapes [33] exposed to chilling.

Other BPs that were highly enriched from the analysis of specifically up-regulated DEGs in Natura were those involved in the maintenance of energy and redox status, including 'glycolysis', 'fatty acid $\beta$-oxidation' and 'pentosephosphate shunt'. Among these DEGs were pyruvate kinase (CUUC9946, CUUC104231), phosphoglycerate kinase (CUUC91403), glyceraldehyde-3-phosphate dehydrogenase (CUUC117427), ribulose-phosphate 3-epime rase (CUUC104592), phosphoribulokinase (CUUC 62669), citrate synthase (CUUC110803), malate dehydrogenase (CUUC107944), and fructose-1,6-bisphosphatase (CUUC111898, CUUC110408). Enhanced expression of these genes may result in activation of carbohydrate catabolism and therefore in a rise of the energy supply for Natura fruit, which agrees with previous reports indicating a higher pool of ATP and high energy status on fruit of this cultivar [7]. Similar findings were revealed by a proteomic analysis in leaves of a cold-tolerant maize genotype [34]. Likewise, Cai and coworkers [35] showed that cold-stored grapes treated with salicylic acid had a better postharvest quality and presented a higher accumulation of an important number of proteins belonging to carbohydrate and energy metabolism pathways. Natura may also increase the ATP production by enhancing respiration, since a delta subunit of two mitochondrial ATP synthase genes (CUUC101699 and CUCC101701) was specifically upregulated in Natura chilled fruit.

The BPs toxin and hydrogen peroxide catabolic processes were also overrepresented in the chilling-tolerant cultivar. These results suggest that concomitant to an increase in the defense response to stress, the trigger of some mechanism of detoxification may allow Natura fruit to avoid or reduce the oxidative stress associated with cold storage. Several DEGs in this group encode detoxification enzymes such as catalase (CUUC61495), peroxidase 2 (CUUC106379), or NADPH-dependent thioredoxin reductase 3-like (CUUC65543), all of them related to ROS scavenging. This differential expression in Natura would explain the lower $\mathrm{H}_{2} \mathrm{O}_{2}$ levels measured in this cultivar; i.e. cold-stored Natura fruit maintained $\mathrm{H}_{2} \mathrm{O}_{2}$ levels similar to fresh or $20{ }^{\circ} \mathrm{C}$ stored fruit, but much lower than those observed in the cold-stored fruit from the sensitive cultivar Sinatra. This is also in accordance with previous reports indicating that the chilling tolerance induced by different postharvest treatments correlated with a high catalase activity and gene expression in zucchini fruit $[12,36]$.

The RNA-Seq data also point to protein degradation as a key mechanism in the acclimation of cold-tolerant fruit to low temperature. Different processes related to proteolysis ('response to misfolded protein', 'proteasome core complex assembly', and 'proteasomal ubiquitindependent protein catabolic processes') were specifically induced in cold-tolerant fruit after 14 days at $4{ }^{\circ} \mathrm{C}$. The ubiquitin-dependent protein degradation involves first the ubiquitination of the target protein by the ubiquitin enzymes in a multi-step process (E1, E2, and E3 enzymes), followed by the degradation of the modified protein by the $26 \mathrm{~S}$ proteasome, a large multi-catalytic endopeptidase complex [37]. It is generally accepted that the ubiquitin-proteasome system (UPS) allows cells to respond rapidly to intracellular signals and changing environmental conditions such as drought, salinity, and cold stress [38]. The UPS function in stress responses is most communly accomplished through targeting and degradation of a negative regulator in response to a stimulus enabling the activation of signaling pathways required for tolerance of the perceived stress [37]. In Natura, many genes encoding for different subunits of the 26S proteasome (CUUC61601, CUUC111088, CUUC114894, etc.) together with two E3 ubiquitin ligases (CUUC62721 and CUUC60741) were up-regulated in cold-stored fruit, reflecting the importance of the UPS in facilitating the response to chilling conditions. 
'Alternative oxidase' (AOX) is another interesting functional category overrepresented in Natura fruit (CUUC91321, CUUC91320, CUUC91319). The alternative pathway of electron transport limits ROS production in mitochondria and has been described as a mechanism to prevent chilling damage in cold-sensitive species [39]. In other freshly harvested fruit such as sweet pepper and tomato, different treatments that increase chilling tolerance such as methyl jasmonate or salicylate also induced the expression of AOX and correlated with CI resistance [40, 41]. Similarly, it is likely that Natura fruit could ameliorate the adverse effect of chilling by an increase in the transcription of the $A O X$ genes.

\section{Molecular mechanisms related to chilling sensitivity in zucchini fruit}

The chilling sensitive cultivar Sinatra showed the opposite profile; no enriched GO terms were found in the upregulated DEGs, but 60 different $\mathrm{GO}$ categories were identified among cold-repressed DEGs. Many of these GO terms were related to response to biotic, abiotic and endogenous stimuli including 'response to cold', 'response to salt stress' or 'response to ABA stimulus'. This enrichment with cold-repressed genes indicates that, contrary to what happens in Natura, chilling-sensitive fruit are unable or have a lower capacity to cope with the adverse environmental conditions imposed. In particular, several of the down-regulated genes belonging to these BPs were related to $\mathrm{Ca}^{2+}$ signaling such as calcium-dependent protein kinases (CUUC118571, CUUC99129), calmodulin like-proteins (CUUC93980, CUUC65863), or calmodulin-domain protein kinases (CUUC118569) (Additional file 6: Table S6), revealing a general repression of $\mathrm{Ca}^{2+}$ signaling in cold-sensitive fruit. These results suggest that similarly to other species, under cold stress conditions $\mathrm{Ca}^{2+}$ signaling must be crucial for the acquisition of cold-tolerance [42, 43].

It is important to highlight that one of the first symptoms of chilling is related to damage of the plasma membrane, explaining why some measurements such us electrolyte leakage and lipid peroxidation are considered as good biochemical markers of chilling damage in zucchini fruit [9]. It is notable that nearly $18 \%$ of specifically cold-repressed DEGs in Sinatra fruit are associated specifically with the plasma membrane. These DEGs are mainly transporters and protein kinases, which may indicate a loss of functionality due to damage in coldsensitive fruit after 14 days of storage at low temperature.

\section{Candidate genes associated with cold tolerance in zucchini fruit}

In an attempt to identify genes that may be involved in the mechanisms that control cold tolerance in zucchini fruit, a series of genes that showed differential expression among cultivars were selected. As described previously, energy and carbohydrate metabolism must play an essential role in the tolerance of zucchini to low temperature. From all the DEGs found in the BPs related to maintenance of energy and redox status, the expression of a malate dehydrogenase (MDH) (CUUC107944) was specifically induced in fruit of the cold-tolerant cultivar. $\mathrm{MDH}$ reaction is involved in central metabolism and redox homeostasis between organelle compartments [44]. In transgenic apple plants, the overexpression of a cytosolic malate dehydrogenase improved their cold and salt tolerance [45], so it is possible that the activation of this enzyme would increase the redox response in zucchini fruit.

Another candidate gene to regulate zucchini response to chilling is the one encoding for phosphatidylinositol:ceramide inositolphosphotransferase 2-like (CUUC60795), which catalyzes the transfer of the phosphorylinositol group from phosphatidylinositol to phytoceramide, an essential step in sphingolipid biosynthesis. These molecules have been proposed to play important roles in signal transduction, membrane stability, host-pathogen interactions, and stress responses [46]. The expression of this gene was strongly down-regulated in the sensitive cultivar; however, the role of these lipids in the response of zucchini fruit to low temperature is unknown. In Arabidopsis, their accumulation in response to cold is increased in wild-type (WT) plants with respect to the cold-sensitive double mutant sld1sld2, although in the slightly more cold-tolerant mutant atbi-1 the levels of sphingolipids were similar to those of WT [47]. Additionally, the virusinduced silencing in tomato plants of a sphingolipid $\Delta 8$ desaturase (SISLD) involved in sphingolipid synthesis induced severe chilling damage after a $4{ }^{\circ} \mathrm{C}$ treatment.

Previous studies showed that peptide transport is involved in stress tolerance. It was reported in Arabidopsis that PTR3-like gene was overexpressed in response to abiotic [48] and biotic stress [49], and the AtPTR3 knockout mutant showed higher sensitivity to bacterial pathogen infection and salt stress, suggesting that this transporter protects against biotic and abiotic stress [49]. In zucchini, we also found that the peptide transporter PTR3-A-like (CUUC107903) and PTR2-like (CUUC89270 and CUUC89268) were specifically upregulated by low temperature in the chilling tolerant cv. Natura.

The signal transduction mechanisms that follow plant stress perception are usually triggered or mediated by TFs. Therefore, TF genes are good candidates for regulating chilling tolerance in zucchini fruit. A large number of TFs have been related to cold stress as well as to other unfavorable conditions in different species [50-52]. Among them, the MYB76-like TF gene (CUUC97743) from 
zucchini was only detectable in fruit of the cold-tolerant cv. Natura, and its expression increased drastically after cold storage. MYB TFs are crucial in regulating the network responses to abiotic and biotic stresses [53]. CUUC97743 encodes a polypeptide of R2R3 MYB type that shows a high homology with MYB TFs linked to processes such as epidermal cell differentiation and trichome development in cucumber $[54,55]$.

Other $T F$ s specifically up-regulated in the tolerant cultivar Natura were a DELLA protein GAIP (CUUC105134) and AP2/ERF domain-containing transcription factor (CUUC104934), whereas five ERFs were specifically down-regulated in the sensitive cultivar, including a C-repeat binding factor (CBF) (CUUC92773). APETALA2 (AP2)/ethylene-responsive-element-binding protein (ER EBP) is a large family of TFs unique to plants that have been implicated in plant responses to stresses such as cold and drought $[56,57]$. The family includes ERF (ethylene responsive factors), and DREB (dehydration responsive element binding proteins) involved in ethylene-related responses. The best known cold regulatory signaling pathway is that mediated by CBF/DREB1 [42], a small subfamily of DREB transcription factors which activates the expression of cold-responsive (COR) genes [58]. The expression of Arabidopsis $C B F 1, C B F 2$, and $C B F 3$ is induced shortly after exposure to low temperature, and their overexpression promotes freezing tolerance in Arabidopsis [59] and other species including tomato, rice, and potato [42], Furthermore, CBF/DREB1s appear to induce the accumulation of DELLA (nuclear growth-repressing proteins), which could be responsible for the growth retardation observed in CBF/DREB1s overexpressing plants [60]. Interestingly, a DELLA protein GAIP-coding gene (CUUC105134) was specifically up-regulated in Natura, while a DELLA protein-coding gene (CUUC81379) was specifically down-regulated in Sinatra concomitant with the down-regulation of the $C B F$, CUUC92773, in this cold-sensitive cultivar.

Regarding $\mathrm{C}_{2} \mathrm{H}_{2}$-type zinc finger transcription factors, ZAT10-like (CUUC61049) showed a very interesting expression profile during zucchini postharvest. In Natura its expression was specifically up-regulated in response to low temperature, while in Sinatra this gene was down-regulated with respect to fruit stored at $20{ }^{\circ} \mathrm{C}$, reaching similar expression levels to fresh harvested fruit. Zhu and coworkers [61] also described the expression of a ZAT10-like protein gene that was induced in mandarin after 60 days of cold storage. Arabidopsis plants overexpressing ZAT10 exhibited growth retardation and enhanced tolerance to drought, salt, osmotic, heat, and oxidative stress, as well as photo-inhibitory light [62-64]. Although Mittler and coworkers [62] observed that knockout and RNAi mutants of Zat10 were more tolerant to osmotic and salinity stress, it has recently been reported that this gene functions as a positive regulator in osmotic stress tolerance, withZAT10 phosphorylation being required for its function in Arabidopsis [65]. We propose that the transcription factors identified in our study are promising candidate genes for controlling chilling tolerance in zucchini, especially those specifically induced by low temperature in the coldtolerant cultivar Natura (MYB76-like, CUUC97743; AP2/ ERF-like, CUUC104934; and ZAT10-like, CUUC61049).

An important group of genes related to stress sensing and signal transduction also increased their transcription in Natura compared to Sinatra. Among them, five different genes encoding 14-3-3 like proteins showed higher expression in Natura fruit after 14 days of storage at $4{ }^{\circ} \mathrm{C}$ (CUUC94909, CUUC94908, CUUC94906, CUUC94907, CUUC111254). It has been reported that phosphorylated like proteins play an important role in abiotic and biotic stress response pathways by interacting and modulating the activity of target proteins [66], or they may interact with components of hormone signaling pathways, such as the ABA signaling pathway [67], that is known to be active under temperature and other stresses. In zucchini, the tolerance to cold storage during fruit postharvest has been associated with an increase in ABA synthesis [3], and higher expression of 14-3-3-like proteins could be related to this behavior.

\section{Conclusions}

In this work, transcriptomic changes that take place in zucchini after cold storage have been compared in two contrasting cultivars for cold tolerance, Natura and Sinatra. The main response of the cold-tolerant cv. Natura was an induction of the mechanisms common to different stress conditions, whereas that of the cold-sensitive cv. Sinatra was a down-regulation of the same mechanisms. This study also highlights the crucial role of some pathways including carbohydrate and energy metabolism, as well as the regulation of transcription and signal transduction in the acquisition of cold tolerance in zucchini during long-term storage. The data suggest the importance of protein trafficking and degradation in the adaptation of the cold tolerant fruit to low temperature. Among the molecular networks related to chilling tolerance that have been detected by functional analysis of RNA-Seq data, different candidates genes have been selected; these genes could be useful as markers for selection of new lines and hybrids in the current breeding programs of zucchini.

\section{Additional files}

Additional file 1: Table S1. Primers pairs used to perform quantitative RT-PCR. (DOC 35 kb) 
Additional file 2: Table S2. RNA-Seq data overview. Numbers of raw and clean reads obtained per sample. (DOC $42 \mathrm{~kb}$ )

Additional file 3: Figure S1. Validation of RNA-Seq results. Scatter plot shows simple linear regression and the R-squared (R2) between Log2 fold change values obtained by RNA-seq $(X)$ and qPCR $(Y)$ for 10 randomly selected genes. (DOC $38 \mathrm{~kb}$ )

Additional file 4: Table S3. DEGs in fruit stored for 14 days at $4^{\circ} \mathrm{C}$ compared to fruit stored at $20^{\circ} \mathrm{C}$ which are specific of Natura fruit (SpecificDEGsNatura Sheet). DEGs in fruit stored for 14 days at $4^{\circ} \mathrm{C}$ compared to fruit stored at $20^{\circ} \mathrm{C}$ which are specific of Sinatra fruit (SpecificDEGsSinatra Sheet). DEGs in fruit stored for 14 days at $4{ }^{\circ} \mathrm{C}$ compared to fruit stored at $20^{\circ} \mathrm{C}$ and that are common to Sinatra and Natura fruit (CommonDEGs Sheet). DEGs in Natura fruit compared to Sinatra fruit before storage (DEGsNATVsSINHarvest Sheet). (XLSX 692 kb)

Additional file 5: Table S4. Functional annotation ( $P$ value $<0.05$ and FDR $<0.05)$ for differentially regulated genes in fresh harvest Natura respect to Sinatra fruit. (XLSX $14 \mathrm{~kb}$ )

Additional file 6: Table S5. Functional annotation ( $P$ value $<0.05$ and FDR $<0.05)$ for differentially regulated genes specific of Natura fruit stored 14 days at $4^{\circ} \mathrm{C}$. (XLSX $\left.61 \mathrm{~kb}\right)$

Additional file 7: Figure S2. Most enriched molecular functions (MF) in percentage of differential expressed genes (DEGs) specific from Natura (A), specific from Sinatra (B), or common in both cultivars (C) exposed to cold storage $\left(4^{\circ} \mathrm{C}\right.$ vs $20^{\circ} \mathrm{C}$ ). (DOC $159 \mathrm{~kb}$ )

Additional file 8: Figure S3. Most enriched cellular components (CC) in percentage of differential expressed genes (DEGs) specific from Natura (A), specific from Sinatra (B), or common in both cultivars (C) exposed to cold storage $\left(4^{\circ} \mathrm{C}\right.$ vs $\left.20^{\circ} \mathrm{C}\right)$. (DOC $\left.121 \mathrm{~kb}\right)$

Additional file 9: Table S6. Functional annotation ( $P$ value $<0.05$ and FDR $<0.05$ ) for differentially regulated genes specific of Sinatra fruit stored 14 days at $4^{\circ} \mathrm{C}$. (XLSX $\left.81 \mathrm{~kb}\right)$

Additional file 10: Table S7. Functional annotation ( $P$ value $<0.05$ and FDR $<0.05)$ for differentially regulated genes common in Natura and Sinatra fruit stored 14 days at $4^{\circ} \mathrm{C}$. (XLSX $\left.62 \mathrm{~kb}\right)$

\section{Abbreviations}

1-MCP: 1-Methylcyclopropene; ABA: Abscisic acid; BP: Biological processes; CC: Cellular component; Cl: Chilling injury; DEG: Differential expressed gene; FC: Log2 fold change; FDR: False discovery rate; FPKM: Fragments per kilobase of transcript per million mapped reads; $\mathrm{GO}$ : Gene ontology; $\mathrm{H}_{2} \mathrm{O}_{2}$ : Hydrogen peroxide; MDA: Malondialdehyde; MF: Molecular functions; PCA: Principal component analysis; TBA: Thiobarbituric acid; TCA: Trichloroacetic acid; TF: Transcription factor

\section{Acknowledgements}

This research has been funded by the Ministerio de Economía y Competitividad and Fondo Europeo de Desarrollo Regional FEDER (Project AGL2014-54598-C2). Fátima Carvajal Moreno and Raquel Rosales López were supported by a Contrato Puente from the Plan Propio of the University of Granada and a Talent Hub (TALENTHUB2014-11), respectively.

\section{Funding}

This research has been funded by the Ministerio de Economía y Competitividad and Fondo Europeo de Desarrollo Regional FEDER (Project AGL2014-54598-C2)

\section{Availability of data and materials}

All data on which the conclusions of the manuscript rely on are available in Additional files. We are in the processes of making available all the clean reads on the NCBI SRA at the moment.

\section{Authors' contributions}

The RNA extraction and most of the analysis were done by RR and FC. The treatments and analysis of quality were done by FP. The validation of the RNA-Seq was done by SM, RR and FC. The data analysis was done by JC, FC and RR. The design of the experiments, part of the analysis and direction of the work was done by MJ and DG. The paper was written by RR, FC and DG. All authors have revised the manuscript and agree to publish it.
Ethics approval and consent to participate

Not applicable.

\section{Consent for publication}

Not applicable.

\section{Competing interests}

The authors declare that they have no competing interests.

\section{Publisher's Note}

Springer Nature remains neutral with regard to jurisdictional claims in published maps and institutional affiliations.

\section{Author details}

${ }^{1}$ Department of Plant Physiology, Facultad de Ciencias, University of Granada, Fuentenueva s/n, 18071 Granada, Spain. ²Department of Biology and Geology, Agrifood Campus of International Excellence (CeiA3), CIAIMBITAL, University of Almería, La Cañada de San Urbano s/n, 04120 Almería, Spain. ${ }^{3}$ Institute for the Conservation and Breeding of Agricultural Biodiversity (COMAV-UPV), Universitat Politécnica de Valencia, Camino de Vera s/n, 46022 Valencia, Spain.

Received: 1 August 2017 Accepted: 28 January 2018

Published online: 07 February 2018

\section{References}

1. Martínez-Téllez MA, Ramos-Clamont MG, Gardea AA, Vargas-Arispuro I. Effect of infiltrated polyamines on polygalacturonase activity and chilling injury responses in zucchini squash (Cucurbita Pepo L.). Biochem Biophys Res Commun. 2002;295(1):98-101.

2. Valenzuela J, Manzano S, Palma F, Carvajal F, Garrido D, Jamilena M. Oxidative stress associated with chilling injury in immature fruit: postharvest technological and biotechnological solutions. Int J Mol Sci. 2017;18(7):1467.

3. Carvajal F, Palma F, Jiménez-Muñoz R, Jamilena M, Pulido A, Garrido D. Unravelling the role of abscisic acid in chilling tolerance of zucchini during postharvest cold storage. Postharvest Biol Technol. 2017;133:26-35.

4. Wang CY. Effect of abscisic acid on chilling injury of zucchini squash. J Plant Growth Regul. 1991;10(1):101.

5. Megías Z, Martínez C, Manzano S, Barrera A, Rosales R, Valenzuela JL, Garrido D, Jamilena M. Cold-induced ethylene in relation to chilling injury and chilling sensitivity in the non-climacteric fruit of zucchini (Cucurbita Pepo L. ). LWT Food Sci Technol. 2014:57(1):194-9.

6. Megías Z, Martínez C, Manzano S, García A, del Mar R-FM, Valenzuela JL, Garrido D, Jamilena M. Ethylene biosynthesis and signaling elements involved in chilling injury and other postharvest quality traits in the nonclimacteric fruit of zucchini (Cucurbita Pepo). Postharvest Biol Technol. 2016; 113:48-57.

7. Palma F, Carvajal F, Jamilena M, Garrido D. Contribution of polyamines and other related metabolites to the maintenance of zucchini fruit quality during cold storage. Plant Physiol Biochem. 2014;82:161-71.

8. Palma F, Carvajal F, Lluch C, Jamilena M, Garrido D. Changes in carbohydrate content in zucchini fruit (Cucurbita Pepo L.) under low temperature stress. Plant Sci. 2014:217-218:78-86.

9. Carvajal F, Martinez C, Jamilena M, Garrido D. Differential response of zucchini varieties to low storage temperature. Sci Hortic. 2011;130(1):90-6.

10. Carvajal Moreno F. Mejora de la vida comercial, calidad y conservación del fruto de calabacín (Cucurbita pepo I.). Universidad de Granada: Granada; 2014.

11. Megías Z, Martínez C, Manzano S, García A, MdM R-F, Garrido D, Valenzuela $J$, Jamilena M. Individual shrink wrapping of zucchini fruit improves postharvest chilling tolerance associated with a reduction in ethylene production and oxidative stress metabolites. PLoS One. 2015;10(7):e0133058.

12. Carvajal F, Palma F, Jamilena M, Garrido D. Preconditioning treatment induces chilling tolerance in zucchini fruit improving different physiological mechanisms against cold injury. Ann Appl Biol. 2015;166(2):340-54.

13. Zheng Y, Fung RWM, Wang SY, Wang CY. Transcript levels of antioxidative genes and oxygen radical scavenging enzyme activities in chilled zucchini squash in response to superatmospheric oxygen. Postharvest Biol Technol. 2008;47(2):151-8. 
14. Mao L-C, Wang G-Z, Zhu C-G, Pang H-Q. Involvement of phospholipase D and lipoxygenase in response to chilling stress in postharvest cucumber fruits. Plant Sci. 2007;172(2):400-5.

15. Heath RL, Packer L. Photoperoxidation in isolated chloroplasts. Arch Biochem Biophys. 1968;125(1):189-98.

16. Alexieva V, Sergiev I, Mapelli S, Karanov E. The effect of drought and ultraviolet radiation on growth and stress markers in pea and wheat. Plant Cell Environ. 2001;24(12):1337-44.

17. Verwoerd TC, Dekker BM, Hoekema A. A small-scale procedure for the rapid isolation of plant RNAs. Nucleic Acids Res. 1989;17(6):2362.

18. Langmead B, Salzberg SL. Fast gapped-read alignment with bowtie 2. Nat Meth. 2012;9(4):357-9.

19. Montero-Pau J, Blanca J, Bombarely A, Ziarsolo P, Esteras C, Martí-Gómez C, Ferriol M, Gómez P, Jamilena M, Mueller L, Picó B, Cañizares J. De novo assembly of the zucchini genome reveals a whole-genome duplication associated with the origin of the Cucurbitagenus. Plant Biotechnol. J; 2017. https://doi.org/10.1111/pbi.12860.

20. Li B, Dewey CN. RSEM: accurate transcript quantification from RNA-Seq data with or without a reference genome. BMC Bioinformatics. 2011;12(1):323.

21. Love MI, Huber W, Anders S. Moderated estimation of fold change and dispersion for RNA-seq data with DESeq2. Genome Biol. 2014;15(12):550.

22. Gentleman RC, Carey VJ, Bates DM, Bolstad B, Dettling M, Dudoit S, Ellis B, Gautier L, Ge Y, Gentry J, et al. Bioconductor: open software development for computational biology and bioinformatics. Genome Biol. 2004;5(10):R80.

23. Huber W, Carey VJ, Gentleman R, Anders S, Carlson M, Carvalho BS, Bravo HC, Davis S, Gatto L, Girke T, et al. Orchestrating high-throughput genomic analysis with bioconductor. Nat Meth. 2015;12(2):115-21.

24. Saeed Al, Sharov V, White J, Li J, Liang W, Bhagabati N, Braisted J, Klapa M, Currier T, Thiagarajan M, et al. TM4: a free, open-source system for microarray data management and analysis. BioTechniques. 2003;34(2):374-8.

25. Conesa A, Götz S, García-Gómez JM, Terol J, Talón M, Robles M. Blast2GO: a universal tool for annotation, visualization and analysis in functional genomics research. Bioinformatics. 2005;21(18):3674-6.

26. Livak KJ, Schmittgen TD. Analysis of relative gene expression data using real-time quantitative PCR and the $2-\Delta \Delta C T$ method. Methods. 2001;25(4): 402-8.

27. Matsui A, Ishida J, Morosawa T, Mochizuki Y, Kaminuma E, Endo TA, Okamoto M, Nambara E, Nakajima M, Kawashima M, et al. Arabidopsis Transcriptome analysis under drought, cold, high-salinity and ABA treatment conditions using a tiling Array. Plant Cell Physiol. 2008;49(8):1135-49.

28. Wang X-C, Zhao Q-Y, Ma C-L, Zhang Z-H, Cao H-L, Kong Y-M, Yue C, Hao X$Y$, Chen L, Ma J-Q, et al. Global transcriptome profiles of Camellia Sinensis during cold acclimation. BMC Genomics. 2013;14(1):415.

29. Cruz-Mendívil A, López-Valenzuela JA, Calderón-Vázquez CL, Vega-García MO, Reyes-Moreno C, Valdez-Ortiz A. Transcriptional changes associated with chilling tolerance and susceptibility in 'micro-tom' tomato fruit using RNA-Seq. Postharvest Biol Technol. 2015;99:141-51.

30. Song Y, Chen Q, Ci D, Zhang D. Transcriptome profiling reveals differential transcript abundance in response to chilling stress in Populus Simonii. Plant Cell Rep. 2013;32(9):1407-25.

31. An D, Yang J, Zhang P. Transcriptome profiling of low temperature-treated cassava apical shoots showed dynamic responses of tropical plant to cold stress. BMC Genomics. 2012;13(1):64

32. Tan H, Huang H, Tie M, Tang Y, Lai Y, Li H. Transcriptome profiling of two asparagus bean (Vigna Unguiculata subsp. sesquipedalis) cultivars differing in chilling tolerance under cold stress. PLoS One. 2016;11(3):e0151105.

33. Rosales R, Romero I, Fernandez-Caballero C, Escribano Ml, Merodio C, Sanchez-Ballesta MT. Low temperature and short-term high-CO2 treatment in postharvest storage of table grapes at two maturity stages: effects on Transcriptome profiling. Front Plant Sci. 2016;7:1020.

34. Wang X, Shan X, Wu Y, Su S, Li S, Liu H, Han J, Xue C, Yuan Y. iTRAQ-based quantitative proteomic analysis reveals new metabolic pathways responding to chilling stress in maize seedlings. J Proteome. 2016;146:1424.

35. Cai H, Yuan X, Pan J, Li H, Wu Z, Wang Y. Biochemical and proteomic analysis of grape berries (Vitis Labruscana) during cold storage upon postharvest salicylic acid treatment. J Agric Food Chem. 2014;62(41):1011825.

36. Palma F, Carvajal F, Jamilena M, Garrido D. Putrescine treatment increases the antioxidant response and carbohydrate content in zucchini fruit stored at low temperature. Postharvest Biol Technol. 2016;118:68-70.
37. Stone SL. The role of ubiquitin and the 265 proteasome in plant abiotic stress signaling. Front Plant Sci. 2014;5:135.

38. Sadanandom A, Bailey M, Ewan R, Lee J, Nelis S. The ubiquitin-proteasome system: central modifier of plant signalling. New Phytol. 2012;196(1):13-28.

39. Purvis AC, Shewfelt RL. Does the alternative pathway ameliorate chilling injury in sensitive plant tissues? Physiol Plant. 1993;88(4):712-8.

40. Fung RWM, Wang CY, Smith DL, Gross KC, Tao Y, Tian M. Characterization of alternative oxidase (AOX) gene expression in response to methyl salicylate and methyl jasmonate pre-treatment and low temperature in tomatoes. J Plant Physiol. 2006;163(10):1049-60.

41. Fung RWM, Wang CY, Smith DL, Gross KC, Tian M. MeSA and MeJA increase steady-state transcript levels of alternative oxidase and resistance against chilling injury in sweet peppers (Capsicum Annuum L.). Plant Sci. 2004; 166(3):711-9.

42. Miura K, Furumoto T. Cold signaling and cold response in plants. Int J Mol Sci. 2013;14(3):5312.

43. Monroy AF, Dhindsa RS. Low-temperature signal transduction: induction of cold acclimation-specific genes of alfalfa by calcium at 25 degrees C. Plant Cell. 1995;7(3):321-31.

44. Tomaz T, Bagard M, Pracharoenwattana I, Lindén P, Lee CP, Carroll AJ, Ströher E, Smith SM, Gardeström P, Millar AH. Mitochondrial Malate Dehydrogenase lowers leaf respiration and alters photorespiration and plant growth in Arabidopsis. Plant Physiol. 2010;154(3):1143-57.

45. Wang QJ, Sun H, Dong QL, Sun TY, Jin ZX, Hao YJ, Yao YX. The enhancement of tolerance to salt and cold stresses by modifying the redox state and salicylic acid content via the cytosolic malate dehydrogenase gene in transgenic apple plants. Plant Biotechnol J. 2016;14(10):1986-97.

46. Sperling P, Heinz E. Plant sphingolipids: structural diversity, biosynthesis, first genes and functions. Biochim Biophys Acta. 2003;1632(1-3):1-15.

47. Nagano M, Ishikawa T, Ogawa Y, Iwabuchi M, Nakasone A, Shimamoto K, Uchimiya H, Kawai-Yamada M. Arabidopsis Bax inhibitor-1 promotes sphingolipid synthesis during cold stress by interacting with ceramidemodifying enzymes. Planta. 2014;240(1):77-89.

48. Karim S, Lundh D, Holmström K-O, Mandal A, Pirhonen M. Structural and functional characterization of AtPTR3, a stress-induced peptide transporter of Arabidopsis. J Mol Model. 2005;11(3):226-36.

49. Karim S, Holmström K-O, Mandal A, Dahl P, Hohmann S, Brader G, Palva ET, Pirhonen M. AtPTR3, a wound-induced peptide transporter needed for defence against virulent bacterial pathogens in Arabidopsis. Planta. 2007; 225(6):1431-45.

50. Dametto A, Sperotto RA, Adamski JM, Blasi ÉAR, Cargnelutti D, de Oliveira LFV, Ricachenevsky FK, Fregonezi JN, Mariath JEA, da Cruz RP, et al. Cold tolerance in rice germinating seeds revealed by deep RNAseq analysis of contrasting indica genotypes. Plant Sci. 2015;238:1-12.

51. Xu W, Jiao Y, Li R, Zhang N, Xiao D, Ding X, Wang Z. Chinese wild-growing Vitis Amurensis ICE1 and ICE2 encode MYC-type bHLH transcription activators that regulate cold tolerance in Arabidopsis. PLoS One. 2014;9(7): e102303.

52. Yang Q-S, Gao J, He W-D, Dou T-X, Ding L-J, Wu J-H, Li C-Y, Peng X-X, Zhang S, Yi $\mathrm{G}-J$. Comparative transcriptomics analysis reveals difference of key gene expression between banana and plantain in response to cold stress. BMC Genomics. 2015;16(1):446.

53. Dubos C, Stracke R, Grotewold E, Weisshaar B, Martin C, Lepiniec L. MYB transcription factors in Arabidopsis. Trends Plant Sci. 2010;15(10):573-81.

54. Zhao J-L, Pan J-S, Guan Y, Zhang W-W, Bie B-B, Wang Y-L, He H-L, Lian H-L, Cai R. Micro-trichome as a class I homeodomain-leucine zipper gene regulates multicellular trichome development in Cucumis Sativus. J Integr Plant Biol. 2015;57(11):925-35.

55. Zhao J-L, Wang Y-L, Yao D-Q, Zhu W-Y, Chen L, He H-L, Pan J-S, Cai R. Transcriptome profiling of trichome-less reveals genes associated with multicellular trichome development in Cucumis Sativus. Mol Gen Genomics. 2015;290(5):2007-18

56. Dietz K-J, Vogel MO, Viehhauser A. AP2/EREBP transcription factors are part of gene regulatory networks and integrate metabolic, hormonal and environmental signals in stress acclimation and retrograde signalling. Protoplasma. 2010;245(1):3-14.

57. Feng J-X, Liu D, Pan Y, Gong W, Ma L-G, Luo J-C, Deng XW, Zhu Y-X. An annotation update via cDNA sequence analysis and comprehensive profiling of developmental, hormonal or environmental Responsivenessof the Arabidopsis AP2/EREBP transcription factor gene family. Plant Mol Biol. 2005;59(6):853-68 
58. Stockinger EJ, Gilmour SJ, Thomashow MF. Arabidopsis Thaliana CBF1 encodes an AP2 domain-containing transcriptional activator that binds to the C-repeat/DRE, a cis-acting DNA regulatory element that stimulates transcription in response to low temperature and water deficit. Proc Nat Acad Sci. 1997;94(3):1035-40.

59. Gilmour SJ, Fowler SG, Thomashow MF. Arabidopsis transcriptional activators CBF1, CBF2, and CBF3 have matching functional activities. Plant Mol Biol. 2004;54(5):767-81.

60. Achard P, Gong F, Cheminant S, Alioua M, Hedden P, Genschik P. The coldinducible CBF1 factor-dependent signaling pathway modulates the accumulation of the growth-repressing DELLA proteins via its effect on Gibberellin metabolism. Plant Cell. 2008;20(8):2117-29.

61. Zhu A, Li W, Ye J, Sun X, Ding Y, Cheng Y, Deng X. Microarray expression profiling of postharvest Ponkan mandarin (Citrus Reticulata) fruit under cold storage reveals regulatory gene candidates and implications on soluble sugars metabolism. J Integr Plant Biol. 2011;53(5):358-74.

62. Mittler R, Kim Y, Song L, Coutu J, Coutu A, Ciftci-Yilmaz S, Lee H, Stevenson B, Zhu J-K. Gain- and loss-of-function mutations in Zat10 enhance the tolerance of plants to abiotic stress. FEBS Lett. 2006;580(28-29):6537-42.

63. Rossel JB, Wilson PB, Hussain D, Woo NS, Gordon MJ, Mewett OP, Howell KA, Whelan J, Kazan K, Pogson BJ. Systemic and intracellular responses to Photooxidative stress in Arabidopsis. Plant Cell. 2007:19(12):4091-110.

64. Sakamoto H, Maruyama K, Sakuma Y, Meshi T, Iwabuchi M, Shinozaki K, Yamaguchi-Shinozaki K. Arabidopsis Cys2/His2-type zinc-finger proteins function as transcription repressors under drought, cold, and high-salinity stress conditions. Plant Physiol. 2004;136(1):2734-46.

65. Nguyen XC, Kim SH, Hussain S, An J, Yoo Y, Han HJ, Yoo JS, Lim CO, Yun D-J, Chung WS. A positive transcription factor in osmotic stress tolerance, ZAT10, is regulated by MAP kinases in Arabidopsis. J Plant Biol. 2016;59(1):55-61.

66. Denison FC, Paul A-L, Zupanska AK, Ferl RJ. 14-3-3 proteins in plant physiology. Semin Cell Dev Biol. 2011;22(7):720-7.

67. Cutler SR, Rodriguez PL, Finkelstein RR, Abrams SR. Abscisic acid: emergence of a core signaling network. Annu Rev Plant Biol. 2010;61:651-79.

\section{Submit your next manuscript to BioMed Central and we will help you at every step:}

- We accept pre-submission inquiries

- Our selector tool helps you to find the most relevant journal

- We provide round the clock customer support

- Convenient online submission

- Thorough peer review

- Inclusion in PubMed and all major indexing services

- Maximum visibility for your research

Submit your manuscript at www.biomedcentral.com/submit 